\title{
Malignant peripheral nerve sheath tumor - a case report and review
}

Authors: Fernando Henrique Batista da Mota ${ }^{1}$, Danielle Rabelo Gonzalez Veldman², Laís Ribeiro Vieira $^{3}$, Igor Diego Carrijo dos Santos$^{4}$, Anna Carolina Araújo Marques ${ }^{5}$, Alessandra Roma Rodrigues $^{6}$ (in memorian)

Translation: Pieter Monteiro da Silva Veldman.

${ }^{1}$ Preceptor of Obstetrics and Ginecology at Ceilandia Regional Hospital

${ }^{2}$ Medical Student at Catholic University of Brasilia

${ }^{3}$ Medical Student at Catholic University of Brasilia

${ }^{4}$ Medical Student at Catholic University of Brasilia

${ }^{5}$ Resident of Obstetrics and Ginecology at Maternal and Child Hospital of Brasilia

${ }^{6}$ Resident of Obstetrics and Ginecology at Ceilandia Regional Hospital

\section{The authors declare no conflicts of interest.}

Correspondences: drgveldman@gmail.com

\begin{abstract}
:
This case report aims to contribute to the understanding and to present a new look on the treatment of a rare, aggressive and poorly understood pathology, known as malignant tumor of the peripheral nerve myelin sheath. The objective of this research is to help building a better understanding of this pathology and to evaluate what is new in diagnosis and treatment. We used PubMed's articles with the descriptors: malignant peripheral nerve sheath tumor, Ki67, and malignant tumor immunohistochemistry of the peripheral nerve sheath. Seventeen articles were selected. We also used the descriptor "sarcoma staging" for the visualization of a book chapter and a journal. Malignant neoplasm of the peripheral nerve myelin sheath is a disease that mainly affects neurofibromatosis-1 or patients with prior radiotherapy, but may occur randomly, as with the patient in question. Due to illness multiple incidence locations, the symptoms may be late and staging is difficult. The staging is performed taking into account the size of the primary tumor, its location, lymph node involvement, presence of distant metastases and degree of cell differentiation. The diagnosis is made after resection of the piece with anatomopathological and immunohistochemical analysis, which may delay the treatment. Therefore, it has been seen that the most common treatment continues to be complete surgery with free margins, but there are promising studies in the genetics field for the treatment and better understanding of this pathology.
\end{abstract}

Keywords: Malignant peripheral nerve sheath tumor, staging, Ki67, s100. 


\section{Introduction:}

Malignant peripheral nerve sheath tumor (MPNST) is rare, consisting of less than $10 \%$ of sarcomas and $1 \%$ of all malignancies.

These morbidities have only two scientifically proven risk factors: neurofibromatosis type 1 (NF1) and previous radiotherapy, the rest of the cases that do not have such factors are considered sporadic. ${ }^{1}$ In a patient with neurofibromatosis type 1 , the incidence increases from 5 to $42 \%$ of cases. ${ }^{2}$ They prevail in females between 30 and 50 years of age, but 10 to $20 \%$ of cases occur in a pediatric population., ${ }^{3,4}$

Several patients present clinical manifestations due to the rapid growth of tumor mass. Commonly, the carriers have pain and sensory and/or motor deficits due to nerve compression. ${ }^{5}$ These tumors originate from any cell of the myelin sheath, such as perineural cells, fibroblasts, or Schwann cells. The diagnosis of this pathology is arduous and its nature is considered aggressive due to poor response to chemotherapy and radiotherapy. The imaging examination of choice is magnetic resonance imaging (MRI) because of the ability to differentiate neurogenic soft tissues from non-neurogenic ones, but other imaging tests may contribute. Computed tomography plays an important role in the evaluation of tumors of retroperitoneal localization and in the detection of metastases. On the other hand, proton emission computed tomography (PET-CT) is essential in the determination of recurrence of the disease and in the detection of metastases. ${ }^{3}$

The gold standard exam to confirm the diagnosis is the histopathological analysis, characterized by alternation of hypocellular and hypercellular areas or a diffuse growth pattern of spindle cells that are asymmetrical with hyperchromatic or corrugated hyperchromatic nuclei arranged in palisade or spiral forms, associated with immunohistochemistry, which $50 \%$ to $90 \%$ of the cases stain for S-100 protein, $50 \%$ for myelin basic protein, $40 \%$ for CD57 and positivity for $\mathrm{p}-53 .^{3,6,7}$

The prognosis depends on the size of the tumor (tumors $>5 \mathrm{~cm}$ have worse prognosis), positive surgical margins, histological differentiation and association with NF1. Local recurrence is between 40-65\%, and recurrence at a distance between $40-68 \%$, with sarcomas having the highest rates of recurrence. Five-year survival rates range from $34-64 \%$. The treatment is primarily surgical and the 
whole extent of the tumor must be excised, because the illness does not have a good response to neoadjuvant treatments..$^{3,5,6,7,8}$

The present case report aims to contribute to the literature of this tumor as yet unknown, but very aggressive, with a high morbidity and mortality rate in 5 years.

\section{Case Report}

Female patient, 51 years old, G4P4A0, with a previous history of uterine myomatosis (3 submucous leiomyomas, $1927 \mathrm{~cm}^{3}$ uterus) that was submitted to total abdominal hysterectomy and bilateral salpingectomy, one year later developed abdominal pain with increased intensity in the last 2 weeks. On physical examination, the patient was hypochromic with erythema and infraumbilical ecchymosis, diffuse light pain on deep palpation, presence of hardened mass in the hypogastrium and left iliac fossa of difficult delimitation, absence of signs of peritoneal irritation. Laboratory examination showing anemia, plaquetosis and high lactate dehydrogenase. A pelvic ultrasound was performed, demonstrating a solid mass image in the pelvis.

Computed tomography showed a large expansive formation of lobed and hypoattenuating contour, previously occupying a large part of the medial and lateral right portions of the abdominal cavity, measuring approximately $22.6 \times 11.4 \times 25.4 \mathrm{~cm}$, with calcifications of permeation, displacement of the intestinal loops to the left lateral portion of the abdominal cavity, in addition to images similar characteristics in the right subdiaphragmatic region, about three, measuring on average $12.2 \times 6.9 \mathrm{~cm}$, compressing the hepatic parenchyma, suggesting secondary involvement (carcinomatosis). It was indicated red blood cells transfusion and subsequent surgery.

During exploratory laparotomy, a large amount of blood was observed in the abdominal cavity, it was resected small intestine, appendix and a mass adhered to the descending colon. During surgery, numerous nodules of mesentery were seen on the anterior and posterior sides of the right hepatic lobe, unresectable due to bleeding. 


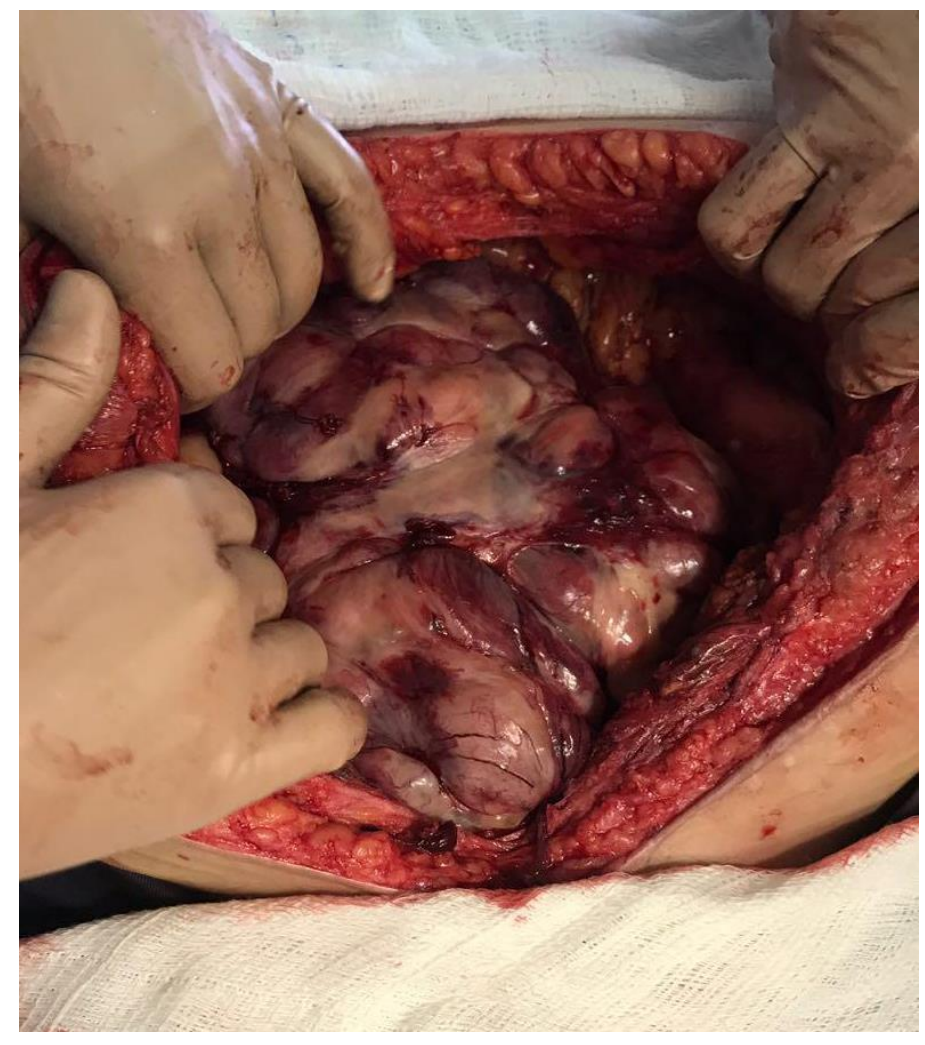

Figure 1- Intraoperative findings of peritoneal spread of malignant retroperitoneal peripheral nerve sheath tumor: focal soft-tissue masses, nodules, or confluent areas within the mesentery.

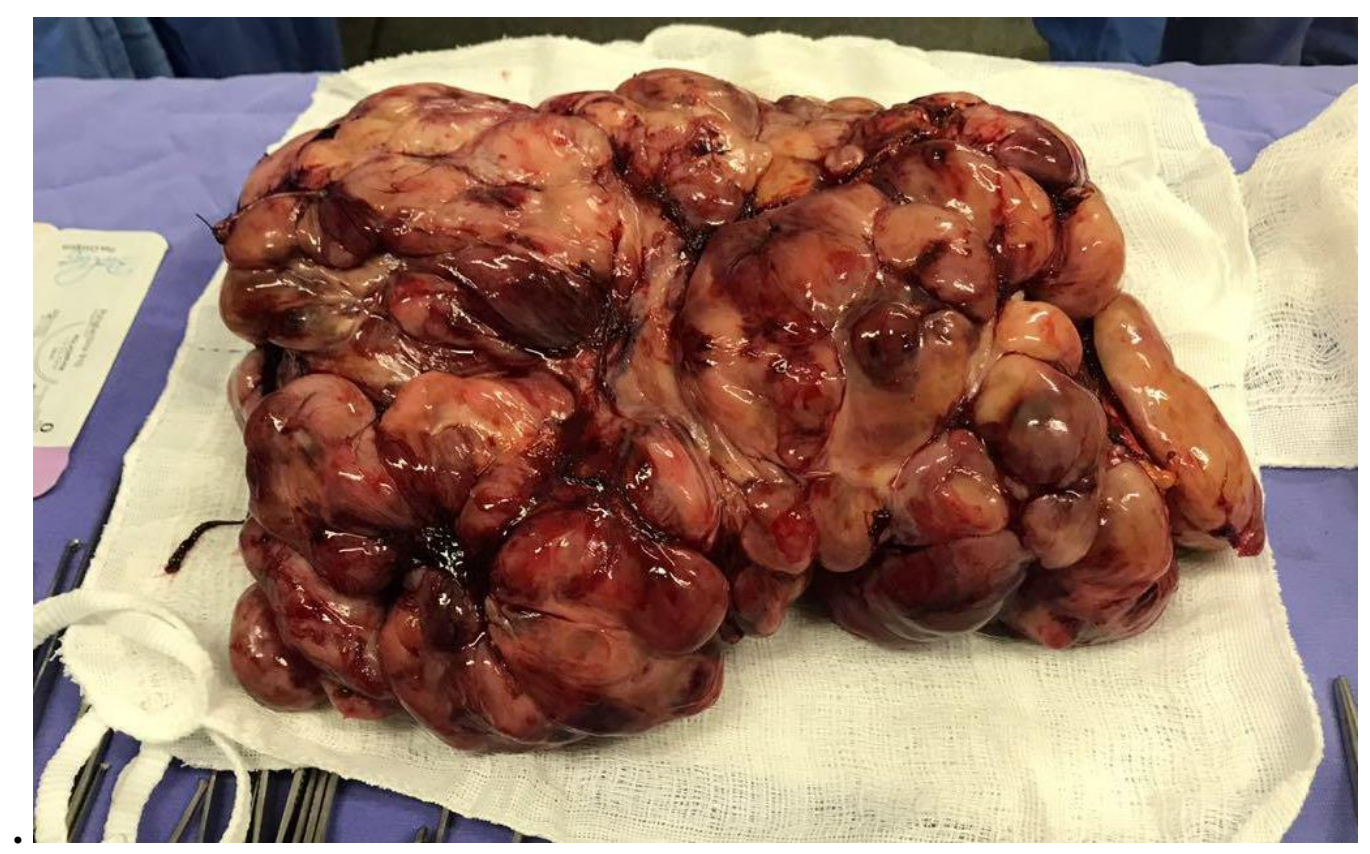

Figure 2- Intraoperative findings: Large mesenteric nodules ressected in abdominal cavity suggestive of retroperitoneal involvement by malignant peripheral nerve sheath tumor. 
The anatomic-pathological analysis of the surgical specimen resulted in tumor-suggestive mesenchymal neoplasia and immunohistochemistry: smooth muscle actin, CD34, desmin and membrane-negative epithelial antigen, ki67 20\%; p16 +; s100 +; PGP 9.5+, suggestive of malignant peripheral nerve sheath tumor.

Six months after surgery, the patient started intense abdominal pain radiated to the lumbar region, polaciuria, chills, weight loss and edema in the lower right limb. At examination, she was hypertensive, hypocorous, dehydrated, abdomen in a board with ecchymosis in the epigastric region and pain in the palpation of the upper floor of the abdomen.

Laboratory tests showed lactate dehydrogenase, alkaline phosphatase, gamma-GT, platelets and prothrombin activation time with significant increase.

Abdominal tomography showed perihepatic and intrahepatic nodules and bulging of the anterior abdominal wall, with an estimated volume of 3,500 cc, as well as a compressive effect on the right kidney, liver and pancreas, and other smaller formations centered on left flank and pelvis.

Due to the clinical picture and surgical impossibility, it was decided to initiate opioid and antiemetic, as well chemotherapy with Genzar and Docetaxel.

Two months later, the patient developed cachexia, abdominal distension and hyperthympanism, with evidence of progression of neoplasia complicated with abscess or enterocolic fistula. Four days later the patient evolved with vomiting and constipation and a significant worsening of the clinical situation, turning the treatment into exclusive palliative care, with subsequent death.

\section{Discussion}

The patient had no pathological history of radiotherapy and neurofibromatosis type 1 (NF1 or Von Recklinghausen's disease), therefore classified as a sporadic case. She presented a slow detection of tumor location (retroperitoneal localization is uncommon, with an incidence of only 1-10\%), compared to a previous history of gynecological surgery and non-specific symptomatology, thus, the long-term diagnosis was only tumoral. The involvement of adjacent organs was able to identify the location of the mass and to program an approach. The second tumor is the main prognostic factor, 
being even used for staging system. ${ }^{9}$ In addition, the tumor is usually well circumscribed, although it does not present a capsule. ${ }^{10,11}$

Due to its rarity and the multiple possible affected locations, it is difficult to perform a staging system for the MPNST or the soft tissue sarcomas in general. This can be achieved through the TNM staging, in which $\mathrm{T}$ is related to the primary tumor, $\mathrm{N}$ related to lymph nodes and $\mathrm{M}$ to metastases, also taking into consideration the histopathological grading according to the following tables (Table 1, 2, 3, 4 and 5). ${ }^{12,13}$

The patient in question presented a stage IV (T2bN0M1, high grade), since the tumor was larger than $5 \mathrm{~cm}$, lymph node involvement was not visualized, but there were hepatic metastases (pulmonary metastasis was not investigated), s100 positive, and Ki67 20\%. Other prognostic factors are free or compromised surgical margins, topography and association with NF1..$^{2,5,7}$

Table 1 - Primary Tumor

\begin{tabular}{|l|l|}
\hline T & Primary tumor \\
\hline TX & Primary tumor cannot be assessed \\
\hline T0 & There is no evidence of primary tumor \\
\hline & $\begin{array}{l}\text { Tumor with } 5 \mathrm{~cm} \text { or less in its largest } \\
\text { dimension: } \\
\text { T1 }\end{array}$ \\
& T1a superficial tumor \\
& T1b deep tumor * \\
\hline & Tumor greater than $5 \mathrm{~cm}$ in greatest dimension \\
T2 & T2a superficial tumor \\
& T2b deep tumor \\
\hline
\end{tabular}

Source: Ministry of Health, TNM 2004

*Retroperitoneal, mediastinal, and pelvic sarcomas are classified as deep.

Table 2- Regional lympho nodes

\begin{tabular}{|l|l|}
\hline N & Regional lympho nodes \\
\hline N0 & Absence of regional lymph node metastasis \\
\hline N1 & Regional lymph node metastasis \\
\hline
\end{tabular}

Source: Ministry of Health, TNM 2004

*Lymph node involvement is rare in soft tissue sarcomas, so when it cannot be evaluated, it is referred to as N0. 
Table 3 - Metastasis at distance

\begin{tabular}{|l|l|}
\hline M & Metastasis at distance \\
\hline M0 & Absence of distant metastasis \\
\hline M1 & Presence of distant metastasis \\
\hline
\end{tabular}

Source: Ministry of Health, TNM 2004

Table 4- Degree of histopathological differentiation

\begin{tabular}{|l|l|l|}
\hline Two-degree system & Three-degree system & Four-degree system \\
\hline Low Grade & Grade 1 & $\begin{array}{l}\text { Grade 1 } \\
\text { Grade 2 }\end{array}$ \\
\hline High Grade & Grade 2 & Grade 3 \\
& Grade 3 & Grade 4 \\
\hline
\end{tabular}

Source: Ministry of Health, TNM 2004

Table 5- Tumor stabilization

\begin{tabular}{|c|c|c|c|c|}
\hline Stadium IA & $\begin{array}{l}\text { T1a } \\
\text { T1b }\end{array}$ & $\begin{array}{l}\text { N0 } \\
\text { N0 }\end{array}$ & M0 & Low grade \\
\hline Stadium IB & $\begin{array}{l}\text { T2a } \\
\text { T2b }\end{array}$ & $\begin{array}{l}\text { N0 } \\
\text { N0 }\end{array}$ & M0 & Low grade \\
\hline Stadium IIA & $\begin{array}{l}\text { T1a } \\
\text { T1b }\end{array}$ & $\begin{array}{l}\text { N0 } \\
\text { N0 }\end{array}$ & $\begin{array}{l}\text { M0 } \\
\text { M0 }\end{array}$ & High grade \\
\hline Stadium IIB & $\mathrm{T} 2 \mathrm{a}$ & N0 & M0 & High grade \\
\hline Stadium III & $\mathrm{T} 2 \mathrm{~b}$ & N0 & M0 & High grade \\
\hline Stadium IV & Any $\mathrm{T}$ & $\begin{array}{l}\text { N1 } \\
\text { Any N }\end{array}$ & $\begin{array}{l}\text { M0 } \\
\text { M1 }\end{array}$ & Any grade \\
\hline
\end{tabular}

Source: Ministry of Health, TNM 2004

The s100 protein is a marker of neural crest differentiation, and may be negative in some patients with MPNST indicating cell differentiation; if it is present, it increases the risk of metastasis, local recurrence and mortality. Ki67, however, represents the mitotic index and is used for prognosis in breast tumors and lymphomas, for example in the case of MPNST Ki67 $\geq 20 \%$ is an independent prognostic factor, with a mortality increase of $2.81 \%$ when compared to Ki67 $<20 \% .^{14}$

The patient of the case, besides presenting the worsening prognostic already mentioned, had numerous implants in abdominal cavity and impossibility of resection of the mass due to its adhesions. 
Besides the rapid development of the tumor, there was no possibility of performing the main therapeutic strategy that we have today, which is surgery with complete resection of the disease.

The treatment is based on local control measures as a way to avoid disease spread. ${ }^{4}$ The surgery must be focused on extensive free margins and adjuvant radiotherapy, although the prognosis is guarded. ${ }^{15}$ The use of radiotherapy is conflicting, some studies have shown improved local control of the tumor and others have not determined this therapy as an improvement in prognosis. Thus, this is a choice in tumors larger than $5 \mathrm{~cm}$, irresponsive to other therapies or with surgical excision very close to the tumor margin. ${ }^{4}$ MPNST is resistant to chemotherapy, but some studies suggest that cases related to NF1 have a worse response to this treatment. Nevertheless, for a better outcome, it is important to initiate chemotherapy in the cases of unresectability, as was done to the patient of this case report, however, she evolved to death after two months. ${ }^{4,1}$

For diagnostic purposes, the standard gold on image method is MRI, with Positron Emission Computed Tomography and contrast computed tomography ideal for evaluating metastasis, which was chosen for the case in terms of cost-benefit. ${ }^{8}$ PET-CT is a good tool for disease staging and for metastasis tracking, with a sensitivity of 89 to $100 \%$ and a specificity of 72 to $95 \% .{ }^{4}$ However, this examination was not carried out in this case probably due to lack of financial resources. ${ }^{16}$

Nevertheless, there is no consensus on the diagnostic criteria, therefore, molecular analysis has been widely accepted. The diagnosis is only conclusive after immunohistochemistry, whereas in the histology MPNST resembles other mesenchymal tumors, with hypo / hypercellularity pattern, fusiform palisade cells with hyperchromatic nuclei, giant cells and necrosis. ${ }^{6,10}$

In immunohistochemistry the most reliable marker of MPNST is the positivity for the s100 protein, despite having a positivity of 50-90\% only. High levels of p53 and Ki-67 are found in MPNST, which was found in the patient. In addition to these, the patient presented positivity for the s100 marker, common in 50 to $60 \%$ of the cases, a marker factor with a high rate of tumor differentiation and characteristic of neoplasms of neural origin, although it is also expressive in other tissues. Other markers are still under study. ${ }^{7,10}$ 
It is essential to discard the main differential diagnoses, which consist of: leiomyosarcoma, angiosarcoma and malignant melanoma. The prognosis is not favorable. MPNST has a high rate of recurrence and metastization of 59\% of cases, as presented in the patient. The main site is pulmonary, however in our case, the dissemination was hepatic. ${ }^{10,2}$

The fatal evolution in relation to the prognostic factors found in the transoperative period (T2bN0M1, high grade) reinforces the need to divulge these cases to the knowledge of the medical community and to discuss the maximum effort in transoperative conduction, in view of the poor response to adjuvant therapies. Currently the field of gene therapy is increasing the survival of patients with cancer and, although we have not yet had an approved therapy for MPNST, this field has been evolving. As an example we have a discovery that in these tumors an overexpression of aryl hydrocarbon receptors (AHR) occur and that when antagonists like CH223191 or trimethoxyflavone tumor are used, apoptosis happens. ${ }^{17}$

It is known that AHR is responsible for activation of $\beta$-cathelin genes that bind to genes that encode myelin, because it was observed that mice in which the aryl hydrocarbon receptor or the RNA of this receptor were not expressed, they had locomotion problems and narrow myelin sheaths. In addition, some genes involved in the tryptophan pathway leading to the synthesis of quinurenine (AHR endogenous ligand) are increased in MPNST, namely IDO1 and TDO2. ${ }^{17}$

\section{Conclusion}

Finally, we consider that one of the great discussions in these cases is undoubtedly the possibility of surgical reintervention to try to complete resection of the disease after diagnostic confirmation whenever there are clinical conditions for such, due to the illness low frequency, impossibility to standardize the patients affected by the disease (as a result of the symptomatology related to site of emergence, histopathological diagnosis and immunohistochemical confirmation are all postoperative), high relapse and low response to adjuvant therapy. 
A promising field is genetic therapy, which will thrive if all cancer treatment centers provide worldwide genomic and immunohistochemical databases for the future development of biomarkers, improving the understanding of the pathology and thus its diagnosis, treatment and prevention.

\section{References}

1. Costa TDA, et al. Tumor maligno de bainha de nervo periférico com apresentação clínica na nasofaringe e cavidade oral de uma criança: relato de caso. Revista do Hospital Universitário Getúlio Vargas. 2011; 10. Disponível em:http://docplayer.com.br/6110815-Tumor-maligno-de-bainha-denervo-periferico-com-apresentacao-clinica-na-nasofaringe-e-cavidade-oral-de-uma-crianca-relatode-caso.html.

2. Panigrahi S, et al. Malignant peripheral nerve sheath tumor presenting as orbito temporal lump: Case report and review of literature. Asian $J$ of Neurosurgery. 2016; 11(2): 170-175. http://dx.doi.org/10.4103/1793-5482.145065. Acessed March 10, 2019.

3. Ayub NEC, et al. Ressecção de Tumor Maligno da Bainha do Nervo Periférico Retroperitoneal: Relato de Caso. Arquivos de Ciências da Saúde. 2016; 23(2):19-22. https://doi.org/10.17696/23183691.23.2.2016.191. Acessed February 15, 2019.

4. Bradford D1, Kim A. Current treatment options for malignant peripheral nerve sheath tumors. Curr Treat Options Oncol. 2015; 16(3): 328. http://dx.doi.org/10.1007/s11864-015-0328-6. Acessed February 12, 2019.

5. Diogo CJ, et al .Tumor maligno da bainha de nervo periférico: relato de caso. Rev Bras Clin Med. 2012; 3(1):69-72. http://files.bvs.br/upload/S/1679-1010/2012/v10n1/a2670.pdf. Acessed February $15,2019$.

6. Guo A, et al. Malignant peripheral nerve sheath tumors: differentiation patterns and immunohistochemical features - a mini-review and our new findings. J Cancer; 2012: 3:303-309. doi:10.7150/jca.4179. Acessed March 17, 2019.

7. Farid M, et al. Malignant peripheral nerve sheath tumors. Oncologist; 2014: 19(2):193-201. doi:10.1634/theoncologist.2013-0328. Acessed February 15, 2019. 
8. Majumdar S, et al. Malignant Peripheral Nerve Sheath Tumor -A Rare Malignancy in Mandible. $J$ Clin Diagn Res. 2016; 10(6): 12-13. doi:10.7860/JCDR/2016/18263.8010. Acessed February 15, 2019.

9. Vasconcelos RAT, et al. Malignant peripheral nerve sheath tumor with and without neurofibromatosis type 1. Arq. Neuro-Psiquiatr.2017; 75(6): 366-371. http://dx.doi.org/10.1590/0004-282x20170052. Accessed on 17 Feb. 2019.

10. Hu SW1, et al. Immunoprofiles in malignant peripheral nerve sheath tumor: three case reports and literature review. Kaohsiung J Med Sci. 2006; 22(3):135-42. https://doi.org/10.1016/S1607-551 X(09)70233-5. Acessed February 5, 2019.

11. Hwang IK, et al. Outcomes of Treatment for Malignant Peripheral Nerve Sheath Tumors: Different Clinical Features Associated with Neurofibromatosis Type 1. Cancer Res Treat. 2017; 49(3):717-726. https://doi.org/10.4143/crt.2016.271. Acessed March 5, 2019.

12. Ministério da Saúde. TNM - Classificação de Tumores Malignos. Rio de Janeiro, BRA: INCA; 2004: 120-124. Disponível em: http://bvsms.saude.gov.br/bvs/publicacoes/inca/tnm2.pdf. Acessed March 17, 2019.

13. Santos, Carlos Eduardo Rodrigues. Sarcomas de Partes Moles. Tumores malignos. p 1761-1774. Disponível em: http://www.cirurgiaonline.com.br/site/images/stories/pdf/sarcomas\%20de\%20partes\%20moles\%20 em\%20dermatologia\%20.pdf. Acesso em 17/03/2019.

14. Yuan Z, et al. Clinicopathological features and prognosis of malignant peripheral nerve sheath tumor: a retrospective study of 159 cases from 1999 to 2016. Oncotarget. 2017;8(62):104785104795. doi:10.18632/oncotarget.18975. Acessed March 18, 2019.

15. Marcal NS, et al. Tumor maligno da bainha dos nervos periféricos do pulmão: A propósito de um caso clínico. Rev Port Pneumol. 2010; 483-492. <http://www.scielo.mec.pt/scielo.php?script=sci_arttext\&pid=S0873$21592010000300011 \& \operatorname{lng}=$ pt\&nrm=iso>. Acessed February 17, 2019.

16. Kara PO, et al. Malignant Peripheral Nerve Sheath Tumor Staging on PET-CT Imaging in a Patient with Neurofibromatosis Type I. Int J Radiol Radiat Ther. 2017; 3(4): 261-262. doi: 10.15406/ijrrt.2017.03.00070. Acessed March 3, 2019. 
17. Shackleford G, et al. Involvement of Aryl hydrocarbon receptor in myelination and in human nerve sheath tumorigenesis. Proc Natl Acad Sci U S A. 2018;115(6):1319-1328. doi:10.1073/pnas.1715999115. Acessed March 17, 2019. 